\title{
Online measurement of work safety culture - statement of research
}

\author{
Izabela Gabryelewicz ${ }^{1, *}$, Patryk Krupa ${ }^{1}$, Joanna Sadłowska - Wrzesińska ${ }^{2}$ \\ ${ }^{1}$ University of Zielona Góra, ul. Szafrana 4, 65-516 Zielona Góra Poland \\ ${ }^{2}$ Poznan University of Technology, ul. Strzelecka 11, Poznań 60-965, Poland
}

\begin{abstract}
The article presents a developed Analytic Platform - Direct Safety, which can be helpful, especially for small enterprises, in determining own policy in the field of occupational safety. Small companies need indicators, on the basis of which they could anticipate and undertake actions aimed at weak sides of the occupational safety. The developed application provides means for analysing a series of aspects, variants and compilations between particular data. One can conduct an analysis anytime, arbitrarily changing selected criteria. The developed tool allows a complex analysis of collected data, considering all values obtained during the analysis of the company's occupational safety state. The article describes the possibilities of the developed Analytic Platform - Direct Safety, on the basis of an analysis of results of the research in the field of measuring the level of the occupational safety culture conducted at a small manufacturing company
\end{abstract}

\section{Introduction}

Each company is an enterprise aimed at supplying particular goods or services [1]. Enterprises are characterised by significant functional and organisational complexities and a large diversification of aims (considering that the most essential aim is profit).

Processes taking place in an enterprise as well as its structure should correspond to features of an intelligent enterprise in order to provide a proper and effective operation [2] (Table 1).

An analysis of the state and functioning of enterprises is multidimensional as enterprises (in major part) have a fractal and hierarchic character. In order to properly function, an enterprise should be:

- safe (lack of accidents and injuries),

- healthy (lack of occupational diseases),

- efficient (high quality production and fully utilised technical and HR infrastructure).

In a general meaning, safety, in its widest meaning, has the largest influence on a proper functioning of an enterprise. Providing safety in a manufacturing enterprise is a complex process and depends on numerous systems. Despite systems of various levels of complexity and automation interpenetrate themselves, the final link of a safety system is a human, at the same time being an addressee of results of the operation of such system [3].

${ }^{*}$ Corresponding author: i.gabryelewicz@ibem.uz.zgora.pl 
Table 1. Comparison of traditional (bureaucratic) and intelligent organisations [2].

\begin{tabular}{|c|c|}
\hline $\begin{array}{c}\text { Traditional organisation } \\
\text { (bureaucratic) }\end{array}$ & $\begin{array}{c}\text { Modern organisation } \\
\text { (based on knowledge) }\end{array}$ \\
\hline $\begin{array}{c}\text { Work fully utilising knowledge of a small part } \\
\text { of employees }\end{array}$ & Work based on knowledge of all employees \\
\hline $\begin{array}{c}\text { Meaningless repetitions of actions and } \\
\text { procedures }\end{array}$ & Work based on innovations \\
\hline Individual or team work & Team work \\
\hline Work consisting in serving functions & Use of skills of teams \\
\hline $\begin{array}{c}\text { Use of individual skills } \\
\text { tong position of managers, often striving } \\
\text { towards autocratic management }\end{array}$ & $\begin{array}{c}\text { Lack of typical managerial posts }- \text { manager as } \\
\text { coach initiator }\end{array}$ \\
\hline $\begin{array}{c}\text { Orientation to company's interior to maintain } \\
\text { internal balance }\end{array}$ & \begin{tabular}{c} 
Orientation on customers \\
\hline Coordination from higher level
\end{tabular} \\
\hline
\end{tabular}

Figure 1 presents elements of an enterprise on which safety depends. Humans have an influence on a proper functioning of particular work safety elements. A human is a superior factor in functioning of each enterprise and a proper operation of each company depends on his/her knowledge, attitude and views [4].

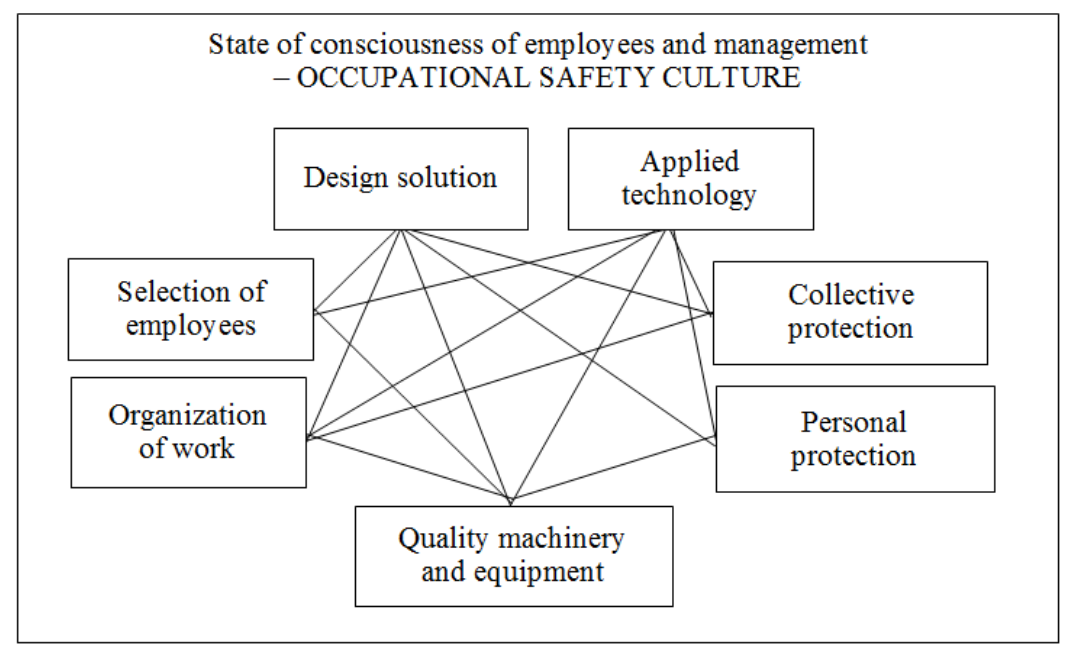

Fig. 1. Relations between elements having an influence on occupational safety state (own elaboration)

Such understanding of the human's function can be specified as occupational safety culture. Measuring occupational safety culture as a determinant of occupational safety is becoming more essential and more popular. There are developed various surveys, control lists, which measure the level of occupational safety culture. The level of occupational safety culture is a symptom thanks to which we are able to predict consequences of activities. Thus, measurements of occupational safety culture should be treated as a quantitative symptom model (cause and effect). A low level of occupational safety culture should be regarded as a symptom of low occupational safety, what results in an increased number and seriousness of work accidents [5]. As a result, such state can cause a higher number of occupational diseases of employees, a greater staff turnover, a lower quality of products or services but also negative effects on the environment quality. 
When searching for reasons of a low level of occupational safety, some features characterising an enterprise do not have a character of reasons when regarded individually. However, when other circumstances occur, they can lead to the risk of employees' loss of life or health, a lower production quality or a negative influence on the environment. Thus, we have to assume that abnormalities in enterprise functioning occur as a result of combined acts and coincidences, i.e. an interference of symptoms, what causes the effect of negative synergy.

\section{Construction of analytical platform - used tool and technologies}

In most of cases, collection of data is only a beginning of studies. The most serious problems occur during their analysis. Analysing numerous collected data, considering various correlations between them, is very difficult or even impossible without proper tools [6-8]. In response to this problem, there was developed the Analytical Platform, which enables multidimensional and multi-aspect analysis of collected data. Such tool is indispensable due to the necessity of fast decision making. The Analytical Platform was developed with a simple operation in mind and due to often limited financial resources, especially in case of small companies, only free software was used.

The application was developed using various programming languages, including: HTML, PHP, SQL, CSS. The application was developed using public free software such as: operating system (Linux Mint) with server software (Apache - www server, MySQL - database, PHP -PHP language parser) and Bluefish -HTML and PHP codes editor.

The platform enables online and offline studies, as well as those in the traditional paper form. Requirements of the developed application depend on the way of conducting research. Requirements for offline work using a single computer without an access to the Internet:

- operating system: Windows, Linux, MacOS,

- server applications (Apache, PHP, MySQL),

- installed Analytical Platform.

In case of launching online surveys, a device with an access to the Internet, should meet the following requirements:

- any operating system with a web browser,

- an access to a network in which the software is installed.

Figure 2 presents the system construction at completing an online survey. Figure 3 presents the system construction at completing a paper survey. In each option, the system includes the following elements:

1. Survey management module - tool for:

- defining survey templates,

- management of survey programs.

2. Completing survey data - module for completing surveys by respondents

3. Analytical Platform - analytical module for:

- generating automatic summary reports,

- creating partial reports (from selected areas),

- complete processing of survey results.

4. Database - including:

- information concerning system users and administrators,

- results of respondents' answers. 


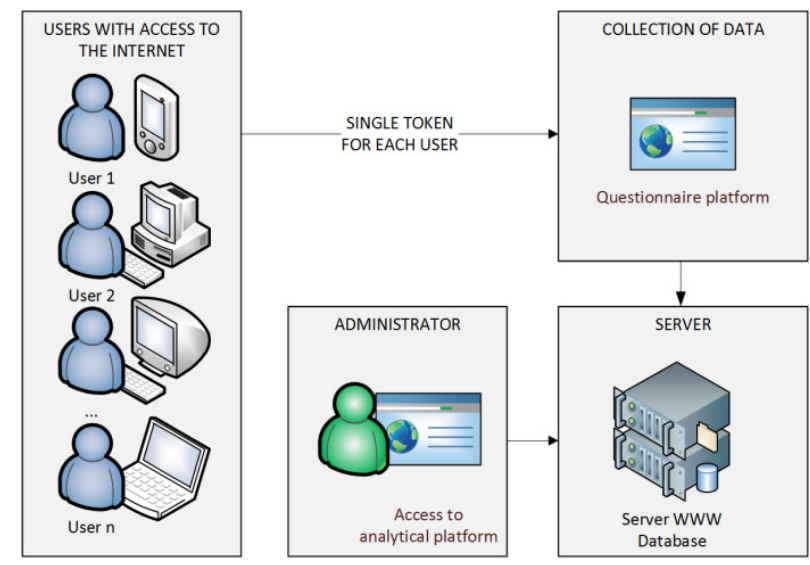

Fig. 2. System construction at completing surveys online.
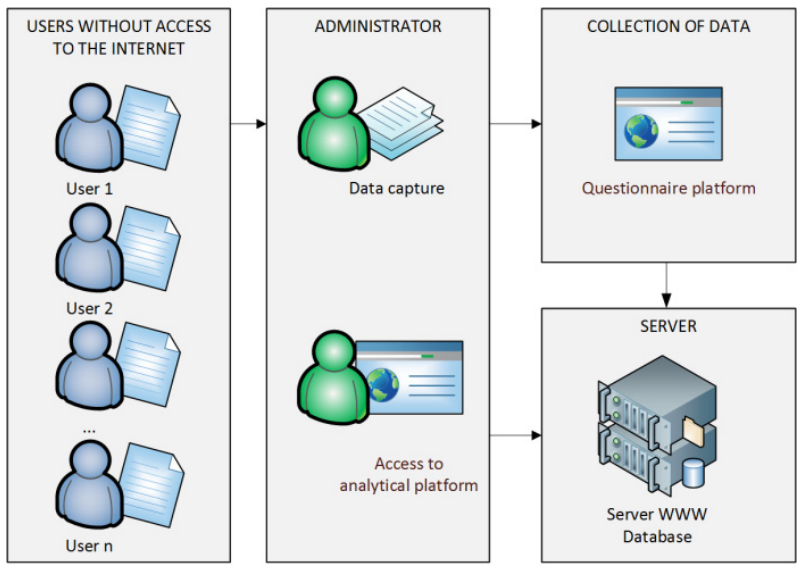

Fig. 3. System construction at completing surveys in paper form.

\section{Analytical platform - user interface - completing survey online}

In order to have an access to complete a survey, one should log in using TOKEN. Tokens are generated by the administrator. A user is redirected to the website where he/she can complete a survey. Generated tokens include encoded information, which allow e.g. company identification, its branch and token status. Status includes information about:

- activity or use of token,

- company for which it was developed,

- generation date,

- use date.

Generation of tokens takes place in the administration panel, when one can determine:

- number of created tokens,

- length (number of characters),

- company for which a particular group of tokens is addressed,

- company branch. 
Figure 4 presents the overview of a snapshot including social and demographic data, necessary for further analysis of obtained data. Figure 5 presents a fragment of a survey, used for studying the level of occupational safety culture of an enterprise.

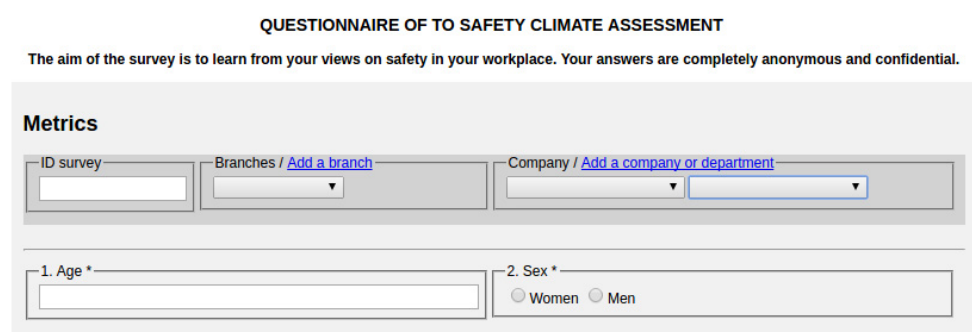

Fig. 4. Survey snapshot with social and demographical data (own elaboration)

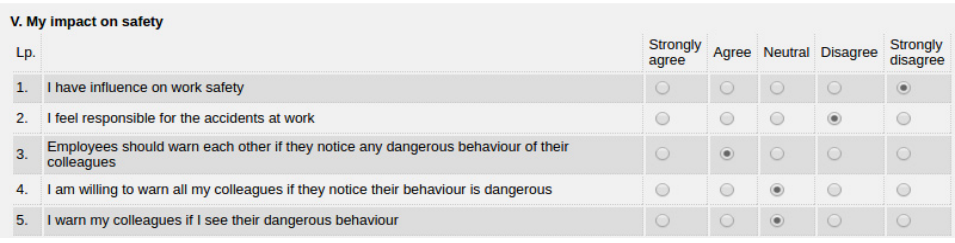

Fig. 5. Part of survey for measuring the level of occupational safety culture of an enterprise (own elaboration).

After completing a survey form, we have possibilities of analysing obtained data.

\section{Analytical platform - user interface - data analysis}

Occupational safety culture module of the Analytical Platform includes a tabular summary of social and demographical data (Figure 6). Such summary is helpful when selecting data for analysing dependences between various social and demographic factors and the level of occupational safety culture, considering particular designata of safety culture. Figure 7 presents a general overview and elements of the interface for analysing results of data collected during survey studies.

\begin{tabular}{|l|r|r|r|r|r|r|r|}
\hline \multicolumn{2}{|c|}{ NUMBER OF RESPONDENTS / EDUCATION } \\
\hline
\end{tabular}

Fig. 6. View on table with collective summary of social and demographic data. 

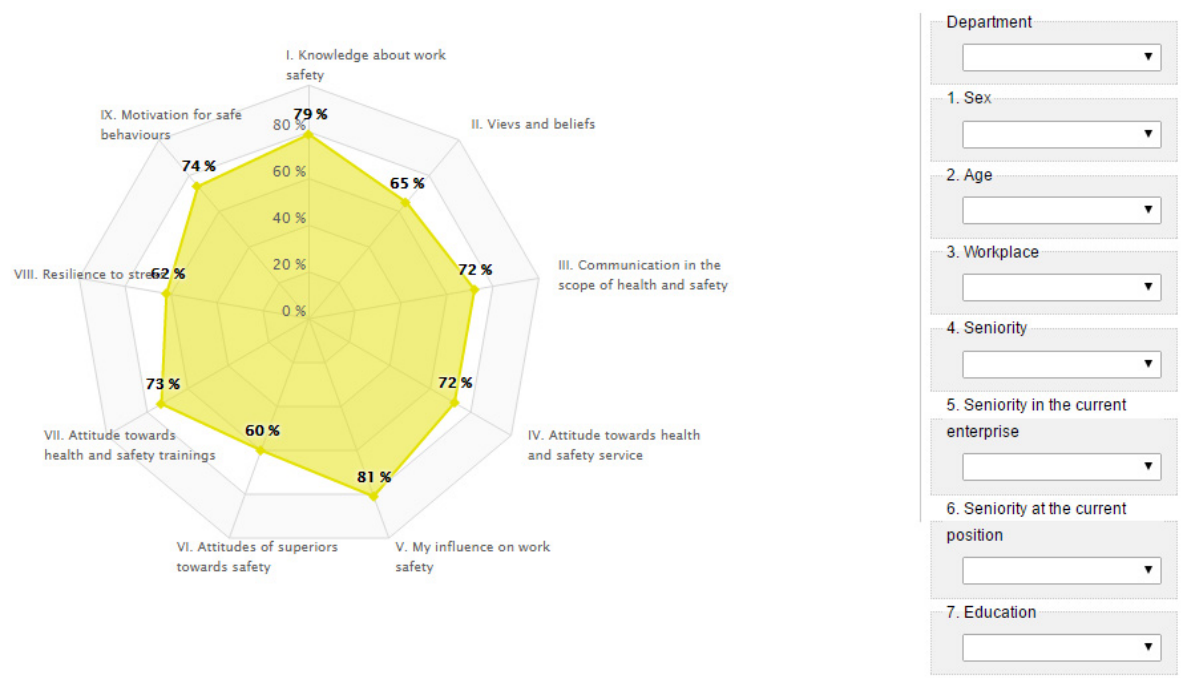

Fig. 7. View on and elements of the interface for analysing research results.

The platform enables a simple analysis of data in accordance to seven basic categories: sex, age, position, general job seniority, job seniority at current workplace, job seniority at current position and education. The Analytical Platform enables analysing of collected data in by single categories. One can check the level of safety culture among employees in accordance to their age (Figure 8) or their education (Figure 10).

Use of indicators (Figure 9 and Figure 11) enables tracing of trends of the level of occupational safety culture depending on a selected analysed social and demographical category.

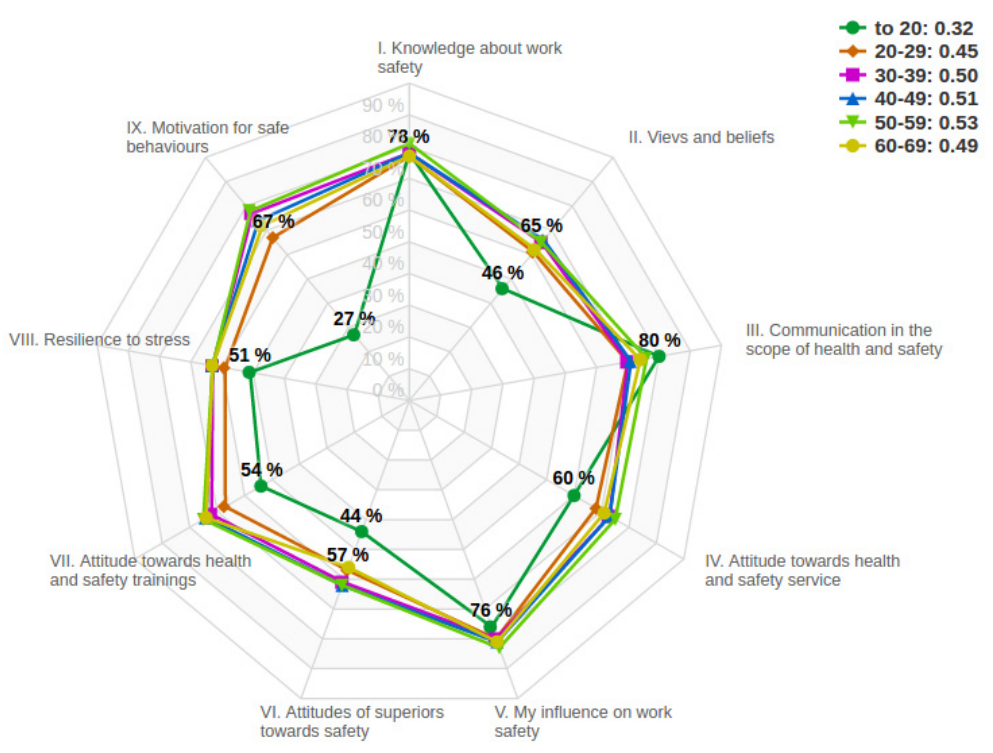

Fig. 8. Generated Safety Culture Net - depending on employee's age (own elaboration). 


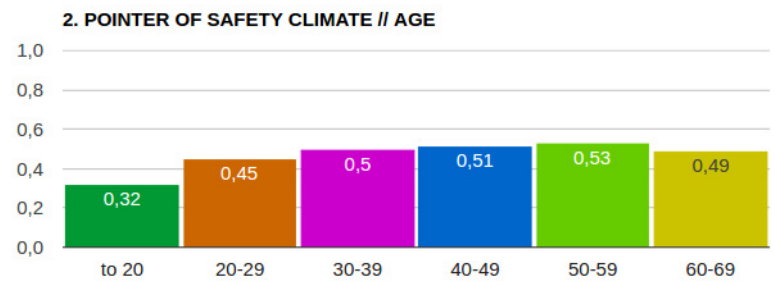

Fig. 9. Generated bar graph depicting the level of safety culture depending on the employee's age in indicative terms (own elaboration).

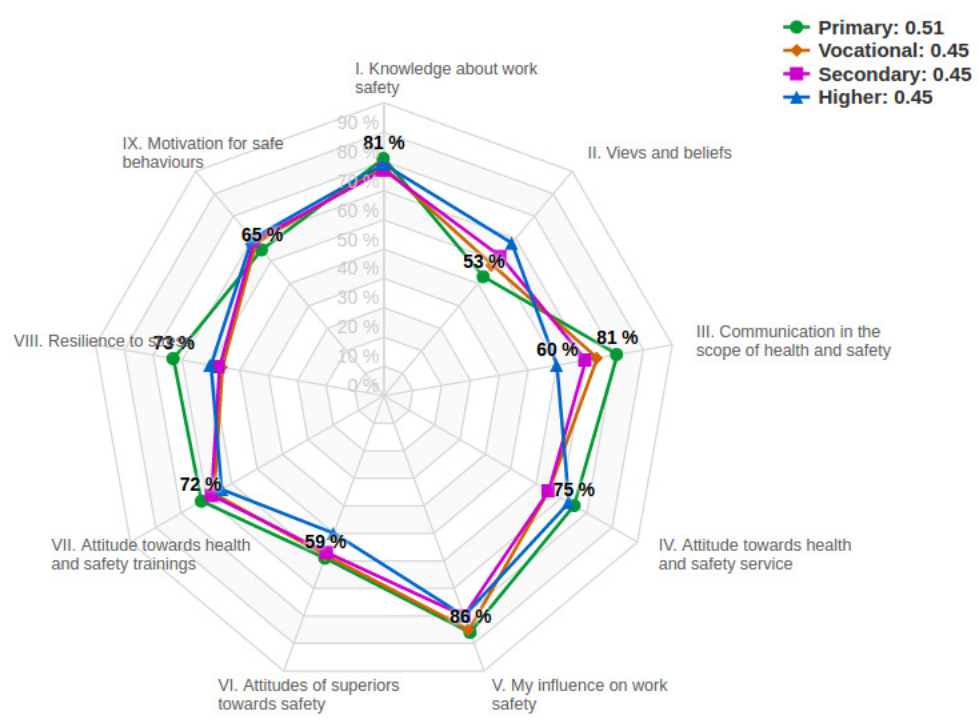

Fig. 10. Generated Safety Culture Net - depending on employee's education (own elaboration).

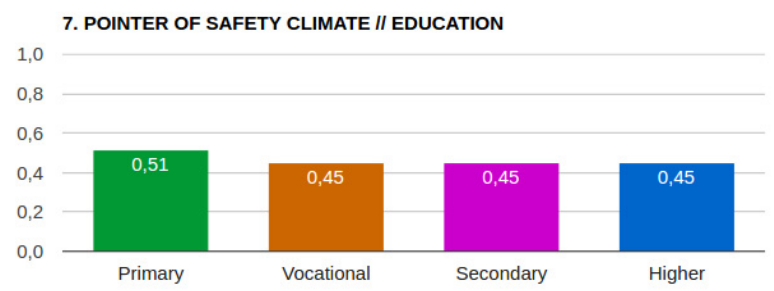

Fig. 11. Generated bar graph depicting the level of safety culture depending on the employee's education in indicative terms (own elaboration).

The Analytical Platform enables also an analysis of data in accordance to selected criteria, which can be freely configured. One can check the level of safety culture among women aged over 29 with secondary education. (Figure 12). Changing the criteria on a side panel, one can analyse the level of safety culture among the youngest employees (regardless sex), with primary education (Figure 13). 


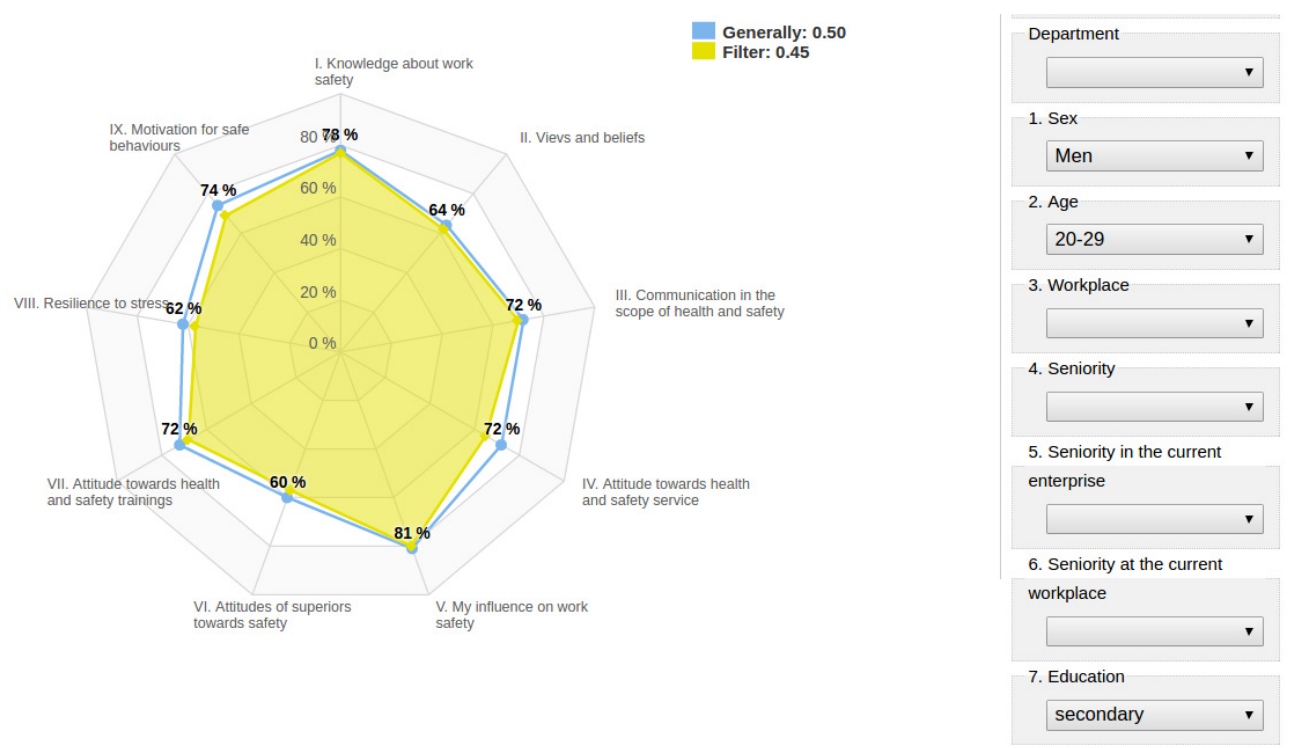

Fig. 12. Generated safety culture net - multi-aspect analysis of criteria (own elaboration).
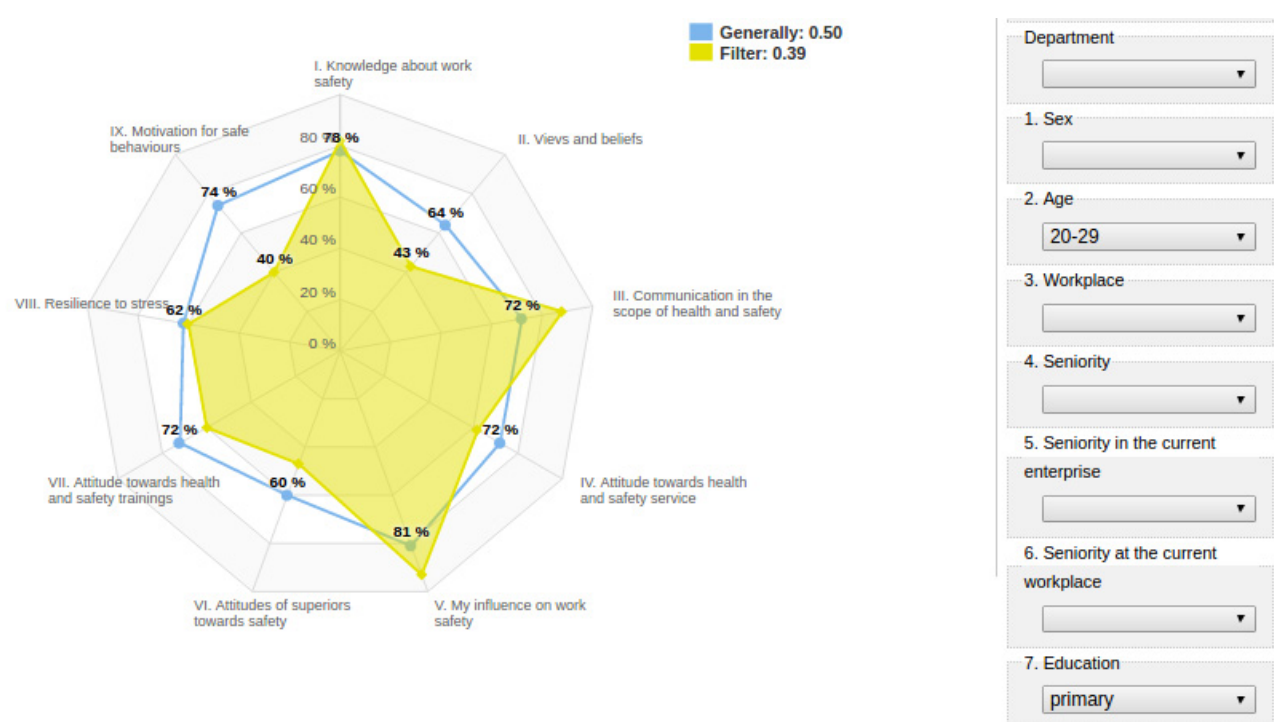

Fig. 13. Generated safety culture net - multi-aspect analysis of criteria (own elaboration).

\section{Analytical platform functionality}

The Analytical Platform was developed using free of charge tools and technologies. It has a friendly and intuitive interface. Other features of the Analytical Platform include:

- It supports studies realised at the same time at various work places, regardless locations. It enables obtaining data without the necessity of visiting plants, what often relates with expensive trips and spent time. Remote data collection facilitates the process of data collecting and enables collection of a larger amount of data during a shorter period of time. 
- It supports cyclically conducted research, regularly repeated. It is possible to consider changes in the group of respondents (staff turnover) in consecutive cycles of studies. It allows defining of new versions of surveys, what is a fundamental research process, after conducting pilot studies.

- The database includes all versions of surveys (before pilot studies and modified after them). The database stores also results of all survey studies.

- The Analytical Platform provides maintenance of confidentiality and anonymity.

- Survey results collected in the database can be used for further analyses, e.g. for statistical aims.

- It enables creation of surveying state (e.g. the number of completed surveys, arranged in accordance to particular branches).

The above mentioned features of the Analytical Platform can be specially useful for comparative studies, when it is necessary to compare results from various analysed companies (e.g. due to a branch, size, social and demographic structure). Stored data can be useful for studies in the time context. When there is a need to study changes taking place in an enterprise:

- in the course of time,

- after introducing particular activities in the field of occupational safety,

- changes of the management,

- other changes.

After that, it would be necessary to check how such changes influence the level of occupational safety culture.

\section{Conclusions}

Research works aimed at decreasing threats are not able to replace indispensable investments in proper functioning of an enterprise [9]. However, even at small resources (often observed at small companies), a multidimensional analysis of the level of safety culture can have an influence on decreasing threats, mainly by shaping proper attitudes of employees and increasing their awareness. Shaping should be preceded by diagnostics in order to be efficient. Purposeful activities aimed at a particular group of employees (considering social and demographical features) will bring better results than general activities.

The presented Analytical Platform is a tool supporting the evaluation of the level of occupation safety culture. In case of collecting large amounts of data, modern technologies are a rational solution to improve work as well as to enable multidimensional analyses. They allow one to determine various correlations, which, using traditional analysis methods, would be impossible (or very difficult due to their time-consuming character) to be determined.

The possibility of comparing study results by an enterprise type or conduction time corresponds to the assumption that abnormalities in an enterprise functioning are not a constant category but they are changing depending on the environment, time, and social and demographic structure of employees and the management.

The most essential activity is obtaining information on the enterprise state. This requires a development or utilisation of proper tools and methods which are objectively oriented, in accordance to the specificity of the enterprise activity and environment in which it functions. Tools and methods and their form should be adjusted to the perceptive, decisive and executive possibilities of a user of a diagnosed enterprise.

The basic aim of developing the Analytical Platform was the necessity of having a tool for analysing a large amount of data and the possibility to determine multidimensional correlations between particular data. 


\section{References}

1. G. W., Werner, Praktyczny Poradnik Konserwacji Maszyn i Urządzeń (Practical Guide to Conservation of Machines and Devices), (WEKA Sp. Z o.o. Wydawnictwo Informacji Zawodowej, Czerwiec 2000)

2. M. Kłak, Zarządzanie wiedzą we współczesnym przedsiębiorstwie (Knowledge management in a modern enterprise), Wydawnictwo Wyższej Szkoły Ekonomii i Prawa im. Prof.EdwardaLipińskiego w Kielcach, 206 (2010)

3. M. Butlewski, M.Slawinska, Ergonomic method for the implementation of occupational safety systems, Occupational Safety and Hygiene Ii, 621, (2014)

4. S. Legutko, Trendy rozwoju utrzymania ruchu urządzeń i maszyn (Development trends in machins operation maintenance), Eksploatacja i Niezawodność 2, 8 (2009)

5. I. Gabryelewicz, P. Krupa, J. Sadłowska-Wrzesińska, IT tool for aiding assessment of safety culture level in an organization, in: J. Grabara and S. Kot (ED): IT Systems and Decisions in Business and Industry Practice, 77 (2015)

6. I. Gabryelewicz, J. Sadłowska-Wrzesińska, E. Kowal, A.Kowal, AHFE, Elsevier.B.V., 962, (2015)

7. J. Sadłowska-Wrzesińska, I. Gabryelewicz, Springer International, CCIS 529, 350, (2015)

8. J. Sadłowska-Wrzesińska, K. Grupka, I. Gabryelewicz, J. Grabara and S. Kot (ED): ITSDBIP, 186 (2015)

9. H. Bałuch, 57, Zeszyt nr 158, Railroading Problems, 57, 158 (2013) 